\title{
Exploring Newmark's Communicative Translation and Text Typology
}

\author{
Wang Zheng \\ Xiamen University Tan Kah Kee College
}

Keywords: communicative; translation; text typology

\begin{abstract}
Translation, as an important means of communication, in all aspects of cross-culture communication, is playing a crucial role. Translation theory's main concerns are to determine appropriate translation methods for the widest possible range of texts or text-categories. When a lot of pragmatic texts, science and technology texts appeared in the translation areas, the interrelation between the text type and transfer method began to arouse the interest of translation scholars. Many translation scholars presented the concept of standards for classifying the correlation between the text type and translation method. There are two famous theorists of Functionalism who made a major contribution to the theory of text typology: Katherina Reiss and Peter Newmark. Peter Newmark, a famous British translation theorist, who linked language function to translation in his theory and further bring the theory of text typology to translation practices. Communicative translation is an important part of Newmark's translation theories. In this thesis, the author will focus on the comparison of semantic translation and communicative translation, then further explore the framework of Newmark's text typology.
\end{abstract}

\section{Peter Newmark and Communicative Translation}

The Definition of Communicative Translation. "Communicative translation attempts to produce on its readers an effect as close as possible to that obtained on the readers of the original. Semantic translation attempts to render, as closely as the semantic and syntactic structures of the second language allow, the exact contextual meaning of the original” (Newmark, 2006: 39). It is obvious that communicative translation focuses on producing an equivalent effect on the target readers. On the contrary, semantic translation remains within the original culture at the author's linguistic level. Newmark's one major contribution to translation is the communicative translation versus semantic translation.

Difference Between Communicative Translation and Semantic Translation. In theory, there are only two methods of translation: communicative translation and semantic translation. There are wide differences between the two methods. Communicative translation addressed itself solely to the second reader, who does not anticipate difficulties or obscurities, and would expect a generous transfer of foreign elements into his own culture as well as his language where necessary. But even here the translator still has to respect and work on the form of the source language text as the only material basis for his work. Semantic translation remains within the original culture and assists the reader only in its connotations if they constitute the essential human (non-ethnic) message of the text.

Communicative translation attempts to produce on its readers an effect as close as possible to that obtained on the readers of the original. Semantic translation attempts to render, as closely as the semantic and syntactic structures of the second language allow, the exact contextual meaning of the original.

The functionalism theory demonstrates the possible translation procedures and the various arguments for and against the use of one translation rather than another in a particular context. Translators should accordingly adopt respective appropriate translation strategies and relative approaches, either semantic translation or communicative translation according to different text types. 


\section{Peter Newmark’s Text Typology}

According to functionalist approaches, it is the intended purpose or function of the target text that determines the translation method. This means that the translator needs to determine the translation purpose first, and next whether the translation intended to show the different aspects of the source text or to achieve the same functions as the original text. Lastly, the translator must then decide the suitable translation strategies and methods. Text typology is a very useful tool to explore translation approaches for different types of text.

Text type and genre are used to refer to a distinctive category of discourse of any type, spoken or written, with and without literary aspiration. Text type as an essential pattern of text embodies linguistic functions, thinking modes and cultural conventions. The study of text types in the text-oriented translation will help the translator to have a thorough understanding of the text and to obtain adequate equivalence in target language text from the source language text. Every text is characterized by one or several basic communication functions. Different text type should require different transfer methods (Reiss 1982:112).

The Classification of Text Type. Based on Karl Buhler's theory of language function and Reiss's text typology, Newmark (1981:21) classifies different texts into three categories: expressive text, informative text, vocative text.

According to Newmark (1998:40), expressive texts include serious imaginative literature, authoritative statements, autobiographies, and personal correspondences; informative texts include textbooks, reports, papers, articles, memos, minutes, and legal documents, etc. with scientific, technological, commercial, industrial, and economic content; vocative texts include notices, propaganda, publicity, and popular fiction.

Text Type and Its Corresponding Translation Criteria and Method. Newmark holds that different texts require different translation criteria and methods. He proposes that semantic translation is used for expressive texts and communicative for informative and vocative texts. In translating expressive texts, the expressive components should be rendered closely. However, for informative and vocative texts, the translator should focus on the accuracy of message and the main force of the texts, trying to produce a pragmatically equivalent effect on readers. Badly and/or inaccurately written passages should be corrected in communicative translation (Newmark,1998: 47).

\section{Translation Methods for Different Text Types}

Translation Methods for Expressive Text. Newmark also points out that the core of expressive text is the author's status in the process of translation. The core of expressive texts is the author's ideology, which is sacred in the texts. The author's personal components constitute the "expressive" elements of an expressive text and become the idiolect which displays the author's personal language style. So, Newmark suggests adopting the approach of semantic translation when translating this type of text. That is, attempt to render, as closely as the semantic and syntactic structures of the second language allow, the exact contextual meaning of the original, in order to display the personal components of the text and make the translated text follow as close to the original as possible. The aim is to highlight the expressive function of the text. (Newmark, 1981).

Translation Methods for Vocative Text. The core of vocative texts is the readership since the status of their authors is not important. Instead, what is important is the effect of information transmission and the readers' affective response, which is to call upon the readers to act, to think, to feel, and to react in the way intended by the text (Newmark, 1998:41). Therefore, to attract readers and perform the vocative function of the text, and achieve the expected effect intended by the original, the translator must observe readers' reading habits and feelings and try to use their familiar expressions. In the process of translating, the translator frequently prefers to adopt the approach of explanation rather than reproduction. The translator has the right to correct or improve the logic of the text, to replace clumsy syntactical structures with elegant ones, to discard any expressions of wayward, obscurities, ambiguity, and tautology, and to correct barriers of idiolect in the text. He 
doesn't have to follow the form of the original. Instead, he can rearrange the sentence structures of the text, and make the translated text natural, fluent, and easily understood (Newmark, 1982:42).

Translation Methods For Informative Text. The function of informative texts focuses on the external situation, the facts of a topic, and the reality outside of the language (Newmark, 1998:40), so the truth conveyed by the information is the core of this type of text. Meanwhile, the author's status in the text is anonymous. The translation of this type calls for receptors' understanding and response, that is, the effect of information transmission. Therefore, Newmark (1982:39) suggests adopting the approach of communicative translation, with the attempt to produce the effect to the target readers as close as possible to that obtained by the original readers, emphasizing the accuracy and truth of the process in information transmission. On this aspect, Newmark's assertion is quite similar to the "functional equivalence" that Nida claims. The readers of a translated text should be able to comprehend it to the point that they can conceive how the original reader of the text must have understood and appreciated it (Nida, 1993:118).

\section{Significance of Newmark's}

The text typology by Newmark is quite brief, definite, and easily utilized, which is not only a guide to literary translation, but more important, a feasible approach to pragmatic translation. According to the three types of texts he mentions above, Newmark (1998:47) further points out that, semantic translation is used for "expressive" texts, communicative for "informative" and "vocative" texts. The difference in the two translation approaches is that the former demands that the translated text should be as close to the original as possible in the form, structure, and word order; and the latter focuses on readers' understanding and response, i.e., the effect of information transmission.

Newmark (1998:42) also claims that, in translation practice, few texts are purely expressive, informative or vocative: most include all three functions, with an emphasis on one of the three. Therefore, the translator must first determine the primary function of a single text, or determine the language function of each part of the same text, and accordingly adopt respective appropriate translation strategies and relative approaches, either semantic translation or communicative translation.

\section{References}

[1] Reiss, K. Text types, translation types and translation assessment. In: Chesterman, A. (ed.) (1989). Readings in Translation Theory. Oy Finn Lectura Ab,1989.

[2] Holz-Manttari, J. Theory and Method [M]. Helsinki: Rodopi, 1991.

[3] Newmark, P. Approaches to Translation [M]. Oxford: Pergamon. 1981.

[4] Newmark, P. A Textbook of Translation [M]. New York: Prentice Hall International, 1988.

[5] Newmark P. 1998. More Paragraphs on Translation [M]. Multilingual Matters Limited.1998.

[6] Newmark, P. (2006). About Translation [M]. Beijing: Foreign Language Teaching and Research Press.

[7] Nida, E. A. and Taber, C. R. The Theory and Practice of Translation [M]. Leiden: The Netherlands, 1964. 